

\title{
A RELAÇÃO ENTRE AS ESTRATÉGIAS DE ENSINO-APRENDIZAGEM E O PROCESSO DE CONSTRUÇÃO DO CONHECIMENTO OBSERVADOS NA DISCIPLINA DE MECÂNICA DOS SOLOS I
}

\author{
LA RELACIÓN ENTRE LAS ESTRATEGIAS DE APRENDIZAJE Y LA \\ CONSTRUCCIÓN DE CONOCIMIENTOS OBSERVADOS EN LA DISCIPLINA \\ MECÁNICA DE SUELOS I
}

\section{THE RELATIONSHIP BETWEEN THE TEACHING-LEARNING STRATEGIES AND THE KNOWLEDGE CONSTRUCTION PROCESS OBSERVED IN THE SOIL MECHANICS I DISCIPLINE}

\author{
Apresentação: Comunicação Oral \\ Lorena Gomes Abrantes ${ }^{1}$; Aline de Oliveira Curty ${ }^{2}$; Ariany Bevilaqua de Andrade ${ }^{3}$; Matheus Pontes Rampazio ${ }^{4}$, \\ Fernanda Rangel de Azevedo de Paula ${ }^{5}$
}

DOI: https://doi.org/10.31692/2358-9728.VICOINTERPDVL.0227

\begin{abstract}
RESUMO
A geotecnia é uma vertente da engenharia civil de grande importância, tendo em vista que a realização de praticamente todo tipo de obra de engenharia depende da interação do que é projetado (estrutura) com o solo ou rocha, logo a disciplina de Mecânica dos Solos I tem por atribuição transmitir aos alunos a mestria sobre o solo e suas propriedades, por meio das mais variadas metodologias. $\mathrm{O}$ trabalho em questão buscou realizar uma análise exploratória sobre as metodologias que auxiliam o ensino da disciplina de Mecânica dos Solos I, no intuito de comparar, futuramente, os períodos anteriores e posteriores à pandemia, avaliando também os impactos que as estratégias adotadas neste período de pandemia provocaram no aprendizado dos discentes. Nesse sentido, com o auxílio de um formulário eletrônico criado unicamente para este fim, foi realizado um diagnóstico da construção do conhecimento na disciplina abordada com os alunos do centro universitário UniRedentor que cursaram a referida disciplina no segundo semestre do ano de 2019 (período este anterior a pandemia). Constatou-se através dessas análises, a eficácia das aulas experimentais em laboratório para o aprendizado dos alunos e a melhoria dos resultados na disciplina, tendo sido observado uma maior preferência por aulas práticas somadas à realização de exercícios em sala de aula para a compreensão da disciplina. Além do estudo de caso realizado, o presente trabalho trouxe, uma discussão narrativa sobre ferramentas adotadas por instituições de ensino diversas abrangendo temas como os contratos de aprendizagem (CAPre), a aprendizagem baseada em problemas (ABP) e a aplicação do Vê Epistmológico de Gowin, todas possibilitando dar sentido e desenvolvimento ao contexto das questões problemáticas do público alvo com o intuito do aperfeiçoamento didático e da melhoria do rendimento acadêmico.
\end{abstract}

\footnotetext{
${ }^{1}$ Doutoranda em Geotecnia, UFRJ, lorena.abrantes@engenharia.ufjf.br

2 Graduanda em Engenharia Civil, UniRedentor, aline.curty90@gmail.com

${ }^{3}$ Graduanda em Engenharia Civil, UniRedentor, arianybevilaqua@gmail.com

${ }^{4}$ Graduando em Engenharia Civil, UniRedentor, matheusrampazio.mr@gmail.com

${ }^{5}$ Mestre em Geotecnia, UENF, fernandarangel@ redentor.edu.br
} 


\title{
ESTRATÉGIAS DE ENSINO-APRENDIZAGEM E O PROCESSO DE CONSTRUÇÃO DE CONHECIMENTO
}

Palavras-Chave: Mecânica dos solos I, ferramentas de ensino, aulas práticas.

\section{RESUMEN}

La geotecnia es una rama de la ingeniería civil de gran importancia, considerando que la realización de prácticamente todo tipo de obra de ingeniería depende de la interacción de lo diseñado (estructura) con el suelo o roca, de ahí la disciplina de Mecánica de Suelos I tiene la tarea de transmitir a los estudiantes el dominio del suelo y sus propiedades, a través de las más variadas metodologías. El trabajo en cuestión buscó realizar un análisis exploratorio sobre las metodologías que ayudan a la enseñanza de la Mecánica de Suelos I, con el fin de comparar, en el futuro, los períodos antes y después de la pandemia, evaluando también los impactos que las estrategias adoptadas en este período de la pandemia hizo que los estudiantes aprendieran. En este sentido, con la ayuda de un formulario electrónico creado exclusivamente para este fin, se realizó un diagnóstico de la construcción del conocimiento en la disciplina dirigido a los estudiantes del centro universitario UniRedentor que tomaron el curso en el segundo semestre de 2019 (este período anterior la pandemia). Se constató a través de estos análisis, la efectividad de las clases experimentales en el laboratorio para el aprendizaje de los estudiantes y la mejora de los resultados en la disciplina, habiéndose observado una mayor preferencia por las clases prácticas sumadas a la realización de ejercicios en el aula para comprender la disciplina. Además del estudio de caso realizado, el presente trabajo trajo consigo una discusión narrativa sobre herramientas adoptadas por diferentes instituciones educativas que abarcan temas como contratos de aprendizaje (CAPre), aprendizaje basado en problemas (ABP) y la aplicación de la Vee Epistemológica de Gowin, todo ello posibilitando dar sentido y desarrollo al contexto de las preguntas problemáticas del público objetivo con el fin de mejorar la docencia y mejorar el rendimiento académico.

Palabras Clave: Mecánica del suelo, herramientas didácticas y clases prácticas.

\begin{abstract}
Geotechnics is a strand of civil engineering of great importance, considering that the realization of practically every type of engineering work depends on the interaction of what is designed (structure) with the soil or rock, therefore the discipline of Soil Mechanics I has the task of transmitting to students the mastery over the soil and its properties, through the most varied methodologies. The work in question sought to carry out an exploratory analysis on the methodologies that help the teaching of Soil Mechanics I, in order to compare, in the future, the periods before and after the pandemic, also evaluating the impacts that the strategies adopted in this period of pandemic caused students to learn. In this sense, with the help of an electronic form created solely for this purpose, a diagnosis of the construction of knowledge was carried out in the discipline addressed with the students of the UniRedentor university center who took the course in the second semester of 2019 (this previous period the pandemic). It was found through these analyzes, the effectiveness of experimental classes in the laboratory for the students' learning and the improvement of the results in the discipline, having been observed a greater preference for practical classes added to the performance of exercises in the classroom to understand the discipline. In addition to the case study carried out, the present work brought, a narrative discussion about tools adopted by different educational institutions covering topics such as learning contracts (CAPre), problem-based learning (PBL) and the application of Gowin's Epistemological Vee, all making it possible to give meaning and development to the context of the problem questions of the target audience in order to improve teaching and improve academic performance.
\end{abstract}

Keywords: Soil mechanics, teaching tools and ratical classes.

\section{INTRODUÇÃO}

As novas tecnologias estão moldando a sociedade mundial e por consequência o mercado de trabalho também sofre constantes mudanças, sendo a qualificação profissional cada vez mais requisitada. Como resultado, as pessoas estão buscando cada vez mais instituições de ensino superior para adquirir a qualificação profissional. 
O ensino superior deve acompanhar tais mudanças buscando, assim, suprir as necessidades dos seus discentes, visto que estes entrarão no concorrido mercado de trabalho atual. Nesse novo cenário o profissional não só deve deter conhecimento, mas também saber analisar, assimilar e resolver problemas.

Acompanhar essas mudanças que o avanço tecnológico traz vem sendo um desafio para as instituições de ensino superior. Segundo Oliveira \& Silva (2015), devem ter como prioridade capacitar o aluno de forma que ele seja capaz de investigar, processar, assimilar, interpretar e refletir sobre as informações que recebe. Ou seja, o papel das IES não é apenas apresentar um conteúdo aos seus alunos, mas também proporcionar atividades em que essas habilidades sejam desenvolvidas, uma vez que os alunos já são adultos ou estão na fase de amadurecimento.

Com o propósito de construir o conhecimento do aluno já é possível encontrar instituições que utilizam estratégias de aprendizagem como a aula expositiva e dialogada, o estudo de caso e também aulas práticas.

Como resultado, o uso da andragogia pode ter relevância no desenvolvimento de estratégias de aprendizagem. Andragogia, segundo Domingues et al. (2019), é uma forma de educação para adultos e separa a forma como estes aprendem no ensino superior das crianças nas escolas. Outra estratégia que pode ser apresentada é Aprendizagem Baseada em Problemas, que segundo Souza \& Dourado (2015) "promove a aquisição de conhecimentos, o desenvolvimento de habilidades, de competências e atitudes em todo processo de aprendizagem".

A inovação tecnológica vem para facilitar e complementar as novas estratégias de aprendizado. Além do mais, os profissionais devem saber utilizar as novas tecnologias para se destacar no mercado de trabalho tornando, assim, uma necessidade para os alunos das Instituições de Ensino. De acordo com Rambaldi (2010), da mesma forma que tudo muda de forma rápida devido às inovações, o ensino também deve mudar para poder, assim, acompanhar as novas necessidades da sociedade.

Uma outra forma estratégica para a aprendizagem dos alunos na IES é a aplicação de Metodologias Ativas (MA). As MA, segundo Souza, Shiguti e Rissoli (2013), possuem o intuito de promover soluções para um problema por meio de análises, pesquisa e exames e também podem ser coletivas e/ou individuais. A metodologia ativa se torna um meio importante para a construção de aprendizado dos alunos, pois exige soluções que condizem com as práticas sociais (SOUZA; SHIGUTI; RISSOLI, 2013).

Como visto, as mudanças na sociedade e, por consequência, as mudanças nas 


\section{ESTRATÉGIAS DE ENSINO-APRENDIZAGEM E O PROCESSO DE CONSTRUÇÃO DE CONHECIMENTO}

necessidades dos profissionais em formação refletem na forma de aprendizagem do ensino superior. Nesse cenário, torna-se imprescindível que as Instituições de Ensino Superior recorram a novas estratégias de aprendizagem em seus cursos. O presente trabalho visa, então, analisar a importância e o impacto da adoção de estratégias de ensino-aprendizagem, ligadas às metodologias ativas (aulas experimentais, exercícios em sala e em grupo, trabalhos práticos), aplicadas na disciplina Mecânica dos Solos I, avaliado por meio da aplicação de formulário do Google Forms.

\section{FUNDAMENTAÇÃO TEÓRICA}

Tendo em vista todas as mudanças que ocorrem na vida dos estudantes no momento em que ingressam na universidade, diversas pesquisas foram realizadas no intuito de prever até que ponto essas mudanças podem afetar a saúde mental dos alunos em questão. Estudos realizados com discentes de uma universidade particular do estado de São Paulo e da Universidade Federal de Itajubá, do curso de engenharia civil, demonstram que grande parte desses alunos consideram negativos os efeitos de suas rotinas universitárias, vindo a apresentar os mais diversos sintomas relacionados a altos níveis de estresse, como ansiedade, desânimo, desmotivação e outras dificuldades emocionais. Dessa forma, destaca-se a importância de prover apoio a esses estudantes, seja de forma psicossocial, seja na forma de apoio pedagógico, por meio das metodologias ativas de aprendizagem. Este último é o foco do artigo em questão (CONGRESSO BRASILEIRO DE EDUCAÇÃO EM ENGENHARIA, 2020).

Pesquisas realizadas com estudantes de engenharia de produção de uma instituição particular de ensino superior e com alunos da Faculdade de Tecnologia de Taquaritinga compararam índices de aprovação e satisfação em turmas em que foram aplicadas as metodologias ativas de aprendizagem, como, por exemplo, a sala de aula invertida. Os resultados demonstraram não apenas o aumento no índice de aprovação das disciplinas, como também o aumento da satisfação e estímulo dos estudantes envolvidos (CONGRESSO BRASILEIRO DE EDUCAÇÃO EM ENGENHARIA, 2020).

\section{Contratos de aprendizagem}

Instrumento de orientação do processo de ensino, os contratos de aprendizagem (CAPre) vêm como uma alternativa à estruturação da forma como o conhecimento é adquirido, contando com experiências e empreendimentos, por sua vez, compartilhados entre todos os envolvidos nas atividades. Desse modo, viabiliza que os aprendizes desenvolvam 
características como o senso de domínio com o plano adotado, ao passo em que os inserem no processo, de forma que participem da elaboração e validação de cada uma das etapas, que envolvem desde o diagnóstico das necessidades de aprendizagem até a avaliação final das atividades executadas (KNOWLES, 1980, apud SANTOS, 2006, p. 4).

Ademais, a utilização de toda a metodologia adotada na aplicação dos CAPre apresenta outros resultados primordiais: permite ao aprendiz gerir os variados processos, negociados por todos os envolvidos, o que tende a desenvolver um senso de propriedade dos seus estudos, diretamente ligada à confiança em sua capacidade, além de levar à cooperação efetiva em questões relevantes do procedimento (STEPHENSON E LAYCOCK, 1993, p.1718, apud SANTOS, 2006, p. 4).

Embora a utilização desse método possa ser de difícil implantação inicial, tendo em vista que, tradicionalmente, o aluno ocupa o papel de mero espectador das aulas, os inúmeros benefícios e potencial de aprendizado apontam ao fato de que deve ser posto em prática (STEPHENSON E LAYCOCK, 1993, p.22, apud SANTOS, 2006, p. 4).

\section{Aprendizagem baseada em problemas}

$\mathrm{Na}$ aprendizagem baseada em problemas (ABP) o aluno é tido como centro da aprendizagem, o que possibilita uma visão transdisciplinar que busca inicialmente o levantamento de questões problemáticas e, num segundo momento, as soluções para cada uma delas, de acordo com cada disciplina, levando em consideração também os níveis de aprendizagem, a fim de possibilitar a produção de conhecimento. Esse método proporciona aos alunos a convivência com as mais diversas opiniões, trazendo ainda um facilitador praticamente inexistente nos métodos tradicionais de ensino: o entendimento da relevância e aplicabilidade dos conceitos, em vez de sua memorização. A ABP possui diversas etapas, sendo a primeira delas a elaboração do contexto problemático, que busca fazer a correspondência entre os conteúdos estudados e sua prática. A segunda parte destaca as questões problemáticas e, a terceira, a resolução dos problemas encontrados. Por fim, apresentam-se os resultados e ocorre a etapa de autoavaliação, resumindo as reflexões e debates dos alunos, de modo a verificar se todas as questões problemáticas foram resolvidas com a metodologia adotada. O professor tutor é o responsável por finalizar o processo, com a avaliação final dos envolvidos (SOUZA; DOURADO, 2015). 


\section{ESTRATÉGIAS DE ENSINO-APRENDIZAGEM E O PROCESSO DE CONSTRUÇÃO DE CONHECIMENTO}

\section{Aplicação do método "Vê de Gowin" no ensino da Geologia}

De forma a tornar os trabalhos práticos nas escolas o mais viável possível, do ponto de vista conceitual, além de mais práticos e desafiadores, uma escola pública da zona norte de Portugal recorreu à utilização do método "Vê Epistemológico de Gowin" no estudo do tema "Tectônica de Placas". Nessa estrutura, o vértice mostra os objetos que estão na base do conhecimento; seu lado esquerdo, a parte conceitual do estudo, envolvendo elementos básicos como os conceitos, princípios e teorias relacionados ao assunto em questão. Já o lado direito é construído em função da investigação imediata dos problemas: nessa parte em específico devem constar as notas e observações a respeito do decorrer do estudo. No centro da estrutura fica a questão problemática que baseia toda a investigação (FONSECA; BARREIRAS; VASCONCELOS, 2005).

No estudo do tema a aplicação do método "Vê de Gowin" possibilitou nortear e desenvolver as atitudes dos alunos frente à problematização das várias demandas envolvidas nos sistemas terrestres, buscando a resolução desses problemas por meio da realização de atividades experimentais. O contexto proposto foi o mais aberto possível, a fim de despertar o interesse dos participantes, algo que foi verificado, além de aproximá-los dos problemas do dia-a-dia, buscando a aplicabilidade dos assuntos no contexto em que se inserem (FONSECA; BARREIRAS; VASCONCELOS, 2005).

\section{METODOLOGIA}

A utilização dos estudos de caso contribui para que possa ser realizada uma investigação que preserva as características eminentes de eventos da vida real. Diferente do que se acreditava anteriormente, as estratégias de pesquisa não devem ser dispostas de forma hierárquica. Dessa forma, os estudos de caso não mais são vistos apenas como ferramenta exploratória, podendo também ser utilizadas de forma descritiva, como no livro Street Corner Society, de William F. Whyte, que o utiliza em todas as etapas da análise (YIN, 2001).

Não sendo, portanto, apenas uma ferramenta a ser utilizada nas etapas iniciais da pesquisa e levando em conta que o foco deste artigo é investigar um fenômeno contemporâneo dentro de seu contexto da vida real - pandemia do coronavírus e sua interferência nos métodos de ensino tradicionais - o estudo de caso auxiliou no diagnóstico da construção do conhecimento nas disciplinas do curso de Engenharia Civil foi realizado com o auxílio de estudos de caso, partindo a princípio da análise da disciplina de Mecânica dos Solos I, buscando, posteriormente, abranger outras disciplinas (YIN, 2001).

No intuito de descobrir como permeou o aprendizado dos discentes no período em que 
perdurou a pandemia, realizando um comparativo com os períodos anteriores e posteriores, foi estruturado um formulário eletrônico que, finalizado, foi disponibilizado aos alunos por meio do Google Forms. Nesse artigo, foi abordada a pesquisa realizada aos discentes no período anterior a pandemia, a fim de avaliar a potencialização do aprendizado dos discentes com a adoção de estratégias de ensino-aprendizagem na disciplina de Mecânica dos Solos I nesse período (segundo semestre de 2019). De posse das informações coletadas definiu-se quais metodologias eram viáveis e em que aspectos cabiam adaptações, a fim de adequá-las ao ensino presencial. Abaixo, fluxograma das etapas:

Figura 01: Fluxograma de etapas da pesquisa bibliográfica

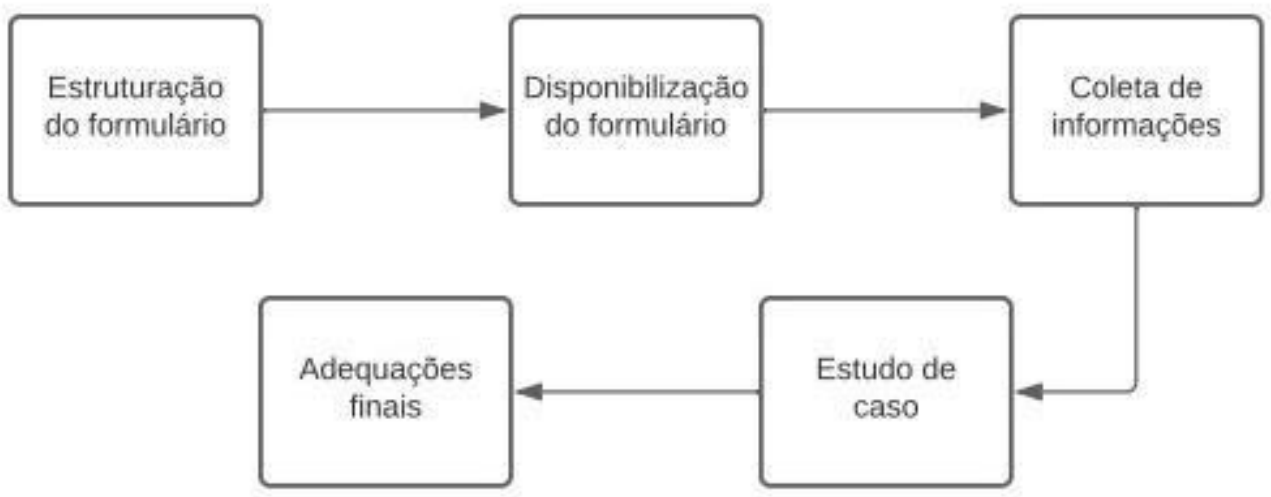

Fonte: Própria (2020).

\section{RESULTADOS E DISCUSSÃO}

Visando uma fundamentação lógica, fora desenvolvida e aplicada uma pesquisa diagnóstica, por meio de um formulário, buscando identificar algumas características do cenário em questão. $\mathrm{O}$ número de alunos inscritos na disciplina durante o segundo semestre do ano de 2019 era de 56 alunos, porém 39 alunos (praticamente 70\% de adesão) concordaram em participar do diagnóstico em questão aplicado por meio do Google Forms. 


\section{ESTRATÉGIAS DE ENSINO-APRENDIZAGEM E O PROCESSO DE CONSTRUÇÃO DE CONHECIMENTO}

Figura 02: Cabeçalho do formulário eletrônico aplicado

\section{A relação entre as estratégias de ensino- aprendizagem e o processo de construção do conhecimento observados na disciplina Mecânica dos Solos I}

Este questionário é parte integrante de uma pesquisa cujo título é "A relação entre as estratégias de ensinoaprendizagem e o processo de construção do conhecimento observados na disciplina Mecânica dos Solos I", podendo ter plena aplicação prática em qualquer outra disciplina.

Gostaria de contar com sua colaboração, por favor.

Seu nome será mantido no anonimato!

Fonte: Própria (2020).

\section{Atividades aplicadas semanalmente em sala de aula}

Quando questionados se a realização de atividades semanais aplicadas contribuiu com o aprendizado e com o desempenho nas avaliações, 70,6\% dos participantes acreditam que este método foi eficaz no processo de aprendizagem e outros $23,5 \%$ veem pelo menos que essa contribuição foi parcial. Fundamentando-se nos dados apresentados, é conclusivo que a maioria dos alunos foi capaz de compreender o método e reagir de forma positiva ao mesmo, aferindo o potencial de uma metodologia ativa - que vê o discente como principal agente de seu aprendizado e o docente como um mero facilitador — na Educação Superior.

Figura 03: Atividades aplicadas semanalmente

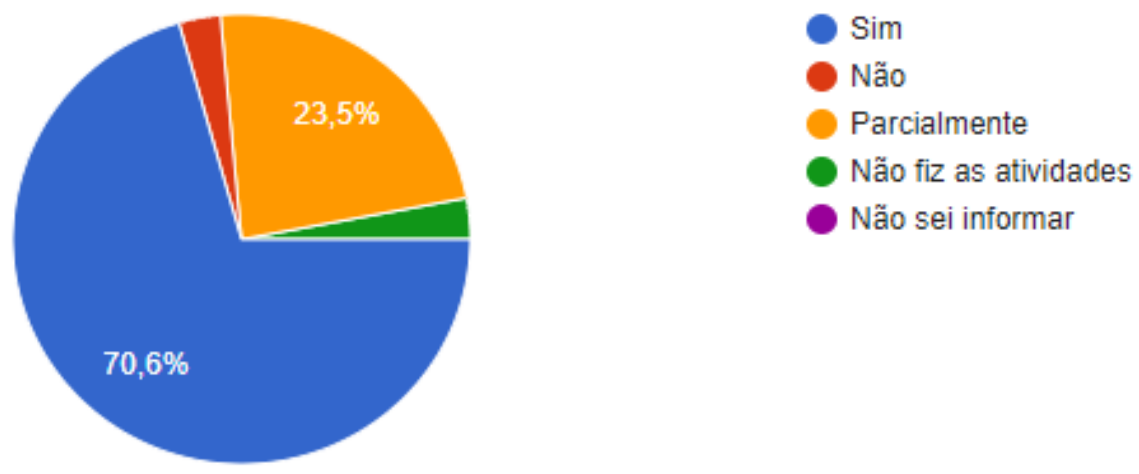

Fonte: Própria (2020).

Outro questionamento foi se os alunos acreditam que a realização de aulas extras contribuiu com o seu aprendizado e com o desempenho nas avaliações, pode-se observar o aumento de credibilidade com $72,2 \%$ de apoio ao método. Outros 8,3\% concordam 
parcialmente com a contribuição. Somado a isto, 16,7\% não puderam assistir às aulas, mas gostariam de ter assistido.

Figura 04: Realização de aulas extras

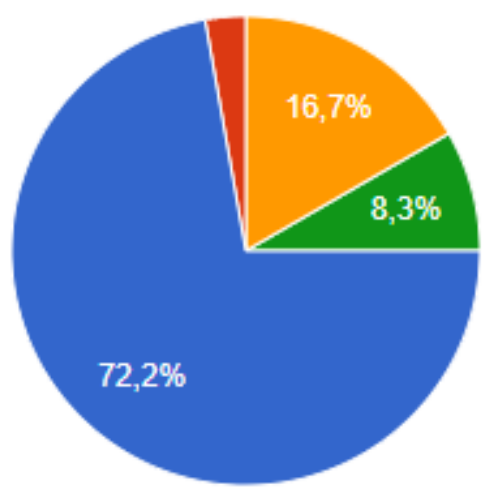

Sim

Não

Não pude assistir às aulas, mas gostaria de ter assistido

- Parcialmente

Não sei informar

Fonte: Própria (2020).

\section{Atividades em sala de aula e em grupo}

No momento em que são perguntados se acreditam que a realização de atividades semanais em sala de aula e em grupos contribuiu com o seu aprendizado e com os seus resultados nas avaliações, pode ser observado um resultado semelhante ao item anterior, com $75 \%$ dos alunos confirmando a contribuição e mais $16,7 \%$ dizendo que ajudaram parcialmente a atingir um melhor desempenho.

Figura 05: Atividades em sala de aula e em grupo

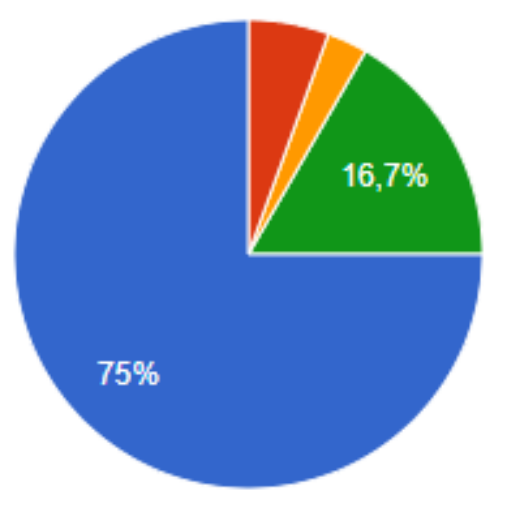

Sim

Não

Para mim, é indiferente realizar as atividades em grupo ou individualmente

Parcialmente

- Não sei informar

Fonte: Própria (2020).

Fora possível notar uma maior aprovação desta prática, mesmo que seja pequena a diferença é possível notar certa preferência dos alunos à realização de atividades em grupo. 


\section{ESTRATÉGIAS DE ENSINO-APRENDIZAGEM E O PROCESSO DE CONSTRUÇÃO DE CONHECIMENTO}

\section{Atividades embasadas em artigos científicos}

Outra questão colocada em pauta foi se as atividades embasadas em artigos científicos contribuíram para potencializar o aprendizado e desempenho nas avaliações. Foram identificadas $86,1 \%$ das respostas confirmando a contribuição e os demais $13,9 \%$ disseram que a prática em questão auxilia, pelo menos, parcialmente a potencialização da aprendizagem.

Figura 06: Atividades embasadas em artigos científicos

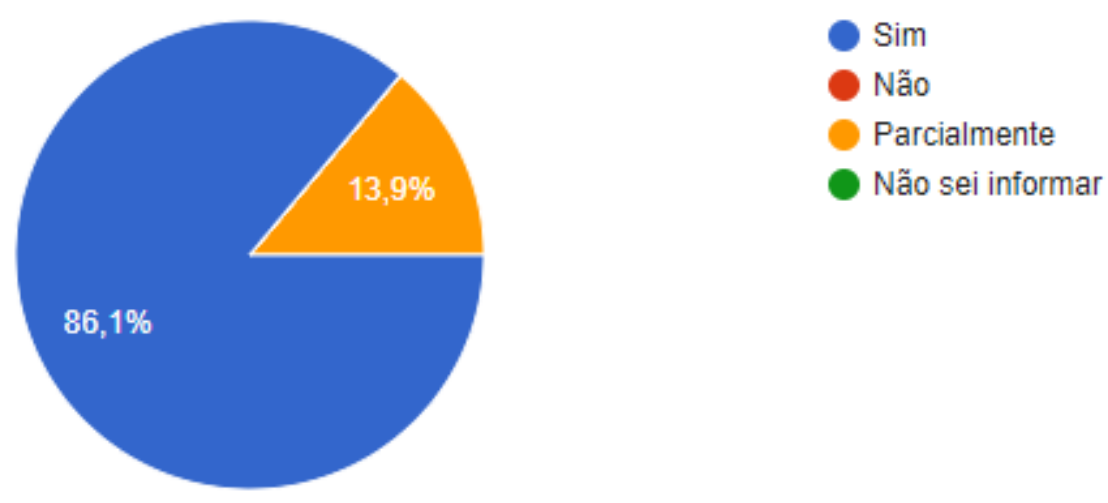

Fonte: Própria (2020).

A partir dos dados apresentados nota-se que os estudantes optam por didáticas que visam facilitar a aplicação prática e o aprofundamento de um determinado assunto, tornandose claro o motivo da grande aprovação deste tipo atividade analisada.

\section{Aulas práticas de laboratório}

Outro questionamento feito foi se as práticas de laboratório foram essenciais para potencializar o seu aprendizado e os seus resultados nas avaliações. As respostas obtidas foram expressivamente positivas contando com a afirmação de $97,2 \%$ dos alunos e os demais $2,8 \%$ concordando parcialmente com a didática. 
Figura 07: Atividades embasadas em prática de laboratório

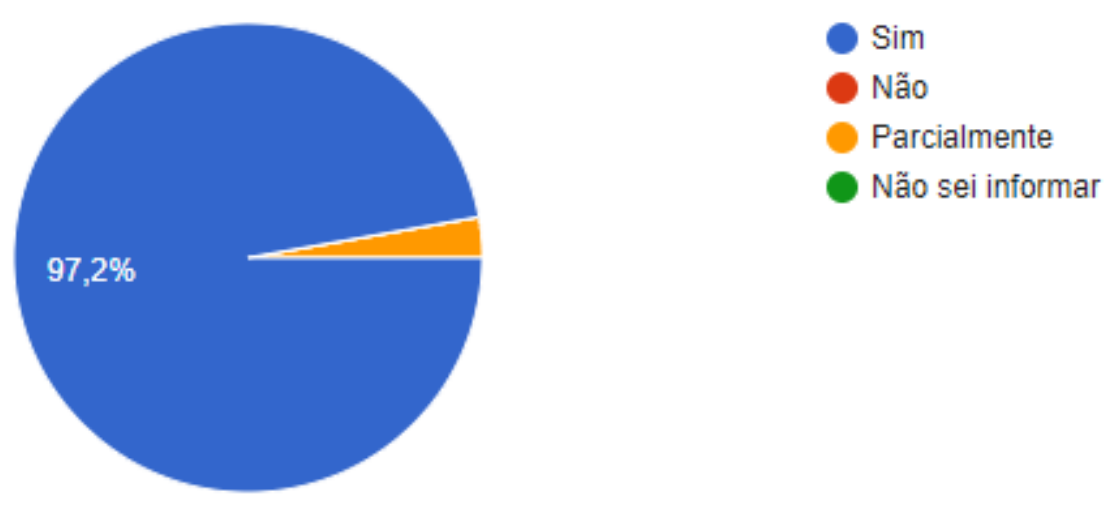

Fonte: Própria (2020).

Apresentando uma aceitação quase unânime essas atividades mostram-se de grande relevância para os alunos, tendo em vista uma maior facilidade de assimilar os temas apresentados nas disciplinas quando postos em prática. Quando relacionado às práticas de laboratório em grupo, há uma pequena redução na concordância $(6 \%)$, porém a aprovação ainda representa uma maioria.

Figura 08: Práticas de laboratório em grupo

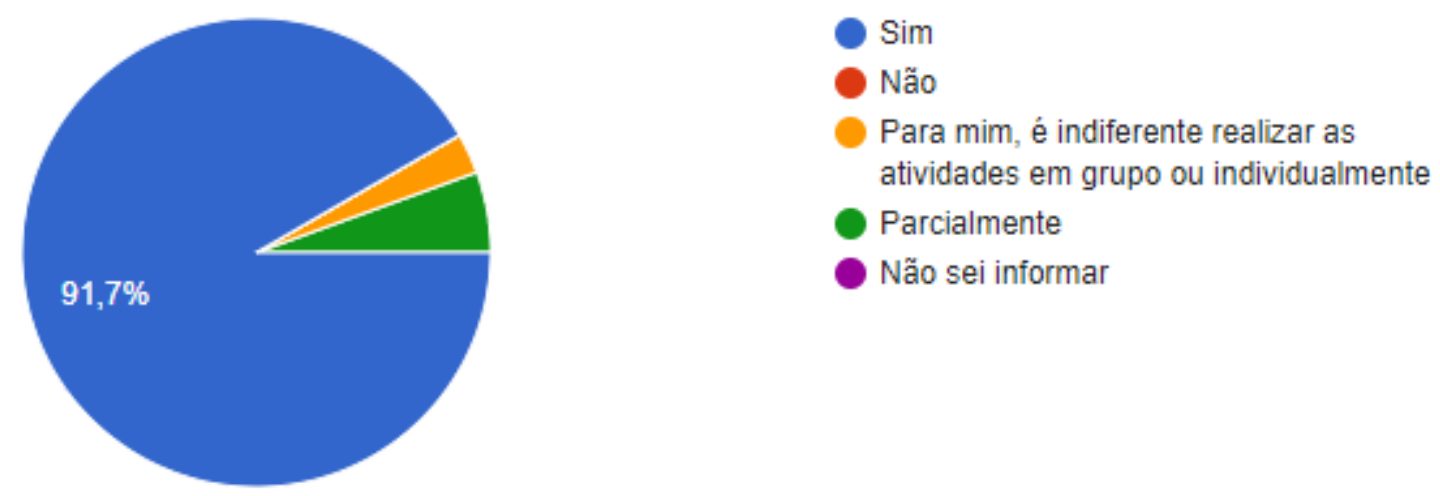

Fonte: Própria (2020).

Quando perguntados se o número de aulas e de práticas de laboratório deveria ser ampliado obteve-se $86,1 \%$ de apoio, mostrando a necessidade de uma ampliação geral carga horária para o ensino da disciplina. 


\section{ESTRATÉGIAS DE ENSINO-APRENDIZAGEM E O PROCESSO DE CONSTRUÇÃO DE CONHECIMENTO}

Figura 09: Ampliar o número de aulas e de práticas de laboratório

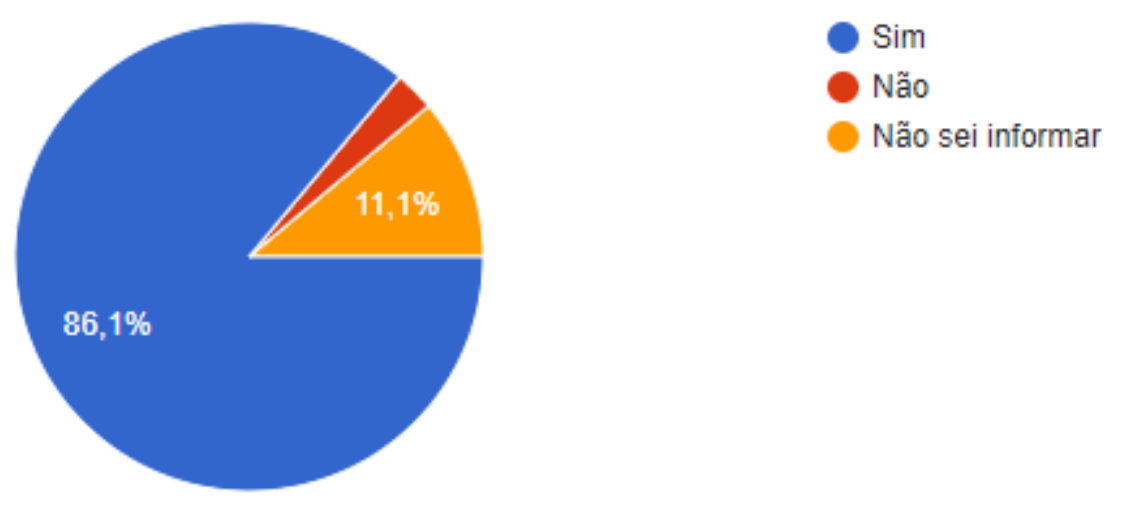

Fonte: Própria (2020).

\section{Novas práticas e ferramentas de ensaio}

Uma das novas práticas propostas foi a utilização de formulários eletrônicos para a realização de atividades, visando uma menor geração de resíduos e consequentemente um impacto positivo no meio ambiente. A aprovação dos alunos foi elevada, apresentando 83,3\% de anuência e mais $8,3 \%$ de apoio parcial, conforme podemos observar no gráfico seguinte.

Figura 10: Atividades por meio de formulários eletrônicos

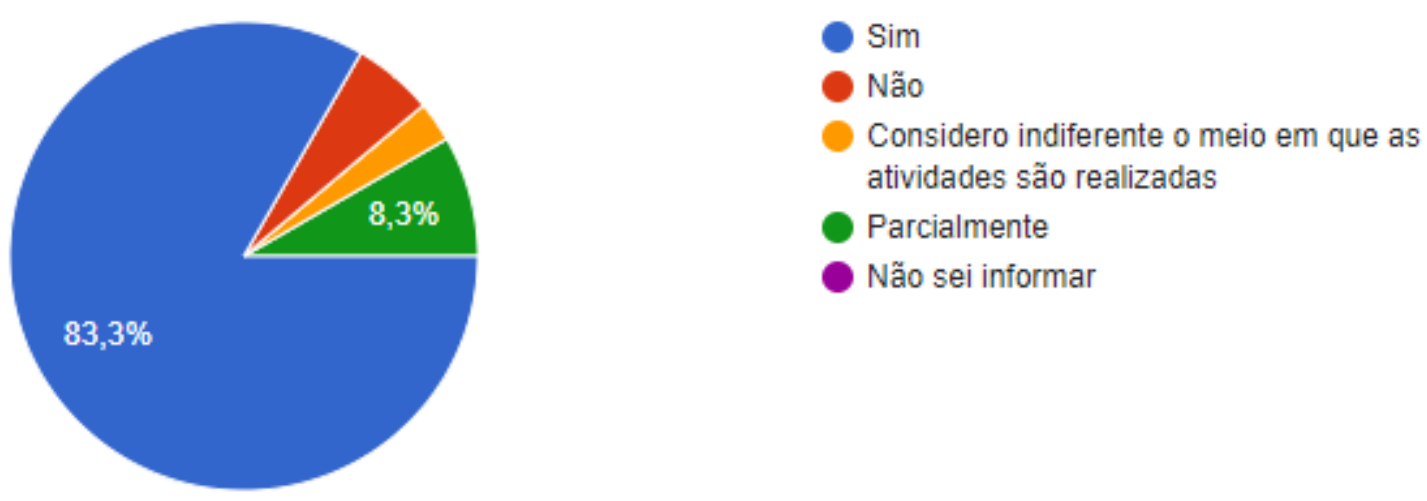

Fonte: Própria (2020).

Porém a mesma ferramenta, quando apresentada como meio de potencialização do aprendizado dos alunos, gerou uma reação oposta à apresentada anteriormente, com apenas $52,8 \%$ de aprovação, mostrando que não há uma preferência dos discentes pela realização de atividades por meio de formulários eletrônicos. 
Figura 11: Atividades semanais por meio de formulários eletrônicos/aplicativos

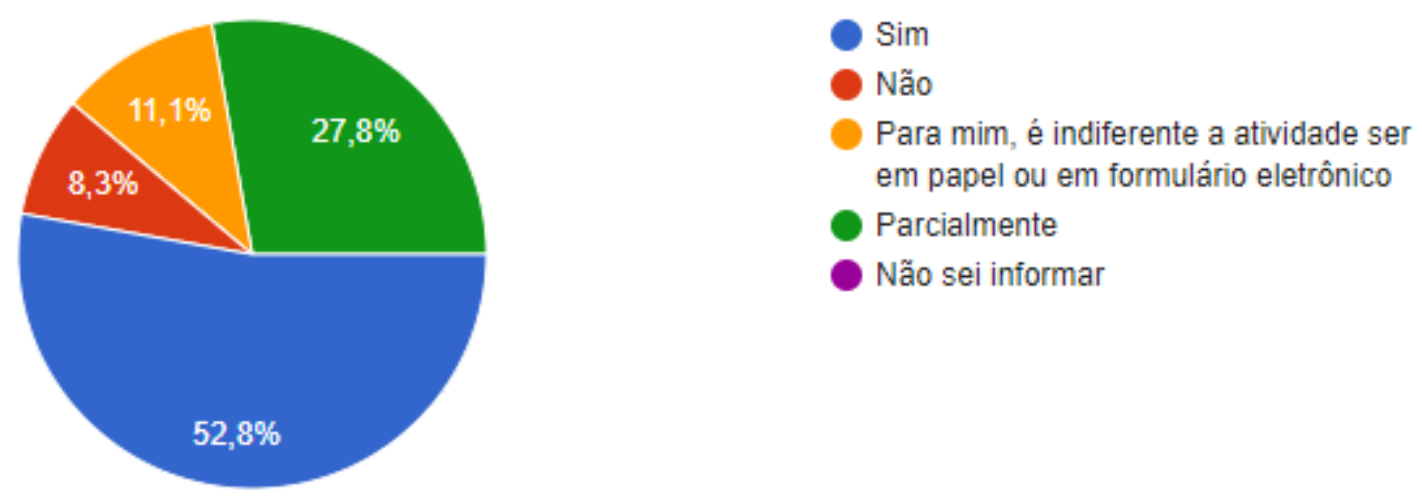

Fonte: Própria (2020).

Em outra proposta, foi questionado se algumas ferramentas de aprendizagem e meios digitais (Instagram, Facebook, Sites, Blog da disciplina e Formulários eletrônicos) teriam potencial para contribuir com o aprendizado, com $72,2 \%$ de respostas afirmativas, este mostra um meio alternativo a ser explorado para instigar e proporcionar melhor instrução sobre a disciplina.

Figura 12: Ferramentas de aprendizagem e meios digitais

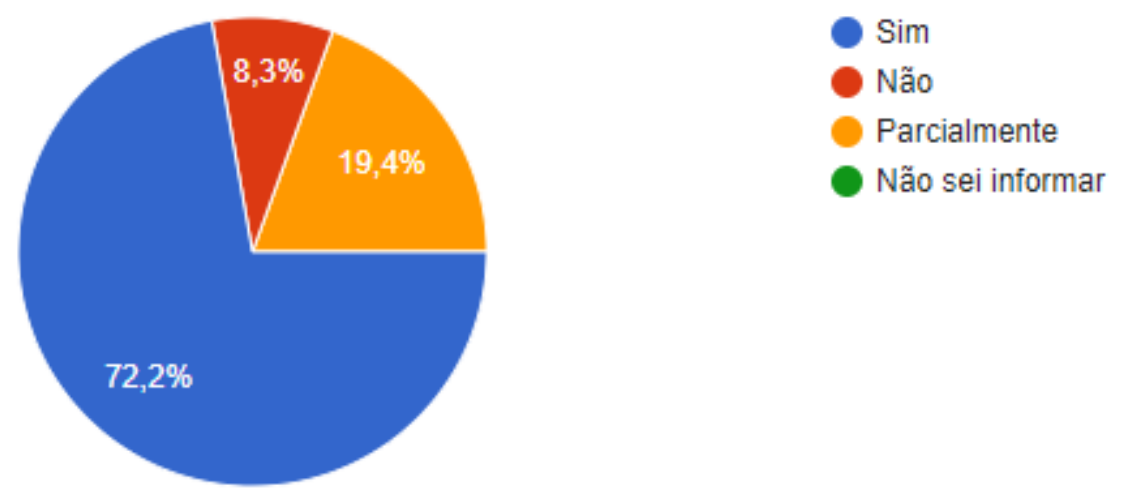

Fonte: Própria (2020).

Também no questionário é interpelado aos alunos se o volume de materiais disponibilizados na plataforma do aluno foi suficiente, as conclusões mostram que 38,9\% acreditam que o volume de materiais seja suficiente e ao menos $44,4 \%$ dos alunos consideram parcial o volume de material disponibilizado. 


\section{ESTRATÉGIAS DE ENSINO-APRENDIZAGEM E O PROCESSO DE CONSTRUÇÃO DE CONHECIMENTO}

Figura 13: Materiais disponibilizados na plataforma



Fonte: Própria (2020).

Além das questões já mencionadas, foi fornecido aos participantes da pesquisa um espaço para que deixassem comentários, críticas e/ou sugestões. No geral, as respostas foram bastante positivas, tais como: “Os ensaios de laboratório possuem uma grande importância na disciplina, pois o aluno começa a enxergar com outros olhos, diferente de quando demonstra esses ensaios em slides e vídeos", "Utilizar um artigo com o tema da matéria também ajuda o aluno a memorizar e aprofundar no assunto abordado, o mais interessante seria de casos reais já acontecidos devido ao solo, como por exemplo o recalque em Santos”. A principal sugestão dada pelos discentes foi a de que mais atividades práticas fossem realizadas, seja por meio de ensaios em laboratório, de discussões, estudos de caso e de visitas de campo.

\section{CONCLUSÕES}

Este trabalho teve como objetivo analisar a importância das atividades aplicadas semanalmente, das atividades em grupos, das atividades embasadas em artigos científicos, das aulas práticas no ensino da disciplina Mecânica dos Solos I, exemplificando ações que contribuíram para motivar a aprendizagem dos alunos. Além disso, o presente trabalho teve como objetivo avaliar os impactos que tais estratégias de ensino-aprendizagem provocaram no aprendizado dos discentes.

No que diz respeito às aulas práticas, foi comprovada sua eficácia em laboratório no aprendizado e na melhoria dos resultados obtidos no curso, cumprindo o objetivo preestabelecido. No que tange os estudos de caso realizados embasados em artigos científicos, observou-se uma potencialização do aprendizado e um maior interesse dos discentes, uma vez que estas atividades permitiram aos mesmos estar envolvidos na prática dos assuntos 
abordados em sala de aula. Em relação às atividades semanais e em grupo, notou-se uma maior adesão dos discentes que contribuíram para um maior contato contínuo com os temas abordados em sala de aula.

\section{REFERÊNCIAS}

CONGRESSO BRASILEIRO DE EDUCAÇÃO EM ENGENHARIA,48.;SIMPÓSIO INTERNACIONAL DE EDUCAÇÃO EM ENGENHARIA DA ABENGE, 3., 2020, Rio Grande do Sul. Anais [...]. Rio Grande do Sul: Universidade de Caxias do Sul, 2020. p. 1-10. Tema: A Saúde Mental do Estudante Da Graduação: Ações de Amparo Psicossocial e Pedagógico.

DOMINGUES, J. V. F. et al. A Relação Entre Aulas Experimentais e o Processo de Construção do Conhecimento Observados na Disciplina Elementos de Geologia. In: CONGRESSO DE ENGENHARIA CIVIL, 6., 2019, Juiz de Fora. Anais [...]. Juiz de Fora: UFJF, 2019. p. 1-14.

FONSECA, P.; BARREIRAS, S.; VASCONCELOS, C. Trabalho experimental no ensino de Geologia: aplicações da investigação na sala de aula. Enseñanza de las Ciencias, 2005 número extra. VII congresso.

OLIVEIRA, N. C.; SILVA, A. L. B. Docência no Ensino Superior: O Uso de Novas Tecnologias na Construção da Autonomia do Discente. Revista Saberes, Rolim de Moura, v. 3, n. 2, p. 3-13, dez. 2015.

RAMBALDI, D. A Inovação na Prática do Ensino Superior. Anuário da Produção Acadêmica Docente, Taubaté, v. 3, n. 4, p. 97-118, 19 mar. 2010. Anual.

SANTOS, C. C. R.. Andragogia: Aprendendo a ensinar adultos. 2006. p. 1-9. Disponível em: < www.aedb.br/seget/arquivos/artigos10/402_ArtigoAndragogia.pdf>. Acesso em: 4 out. 2020.

SOUZA, C. V.; SHIGUTI, W. A.; RISSOLI, V. R. V. Metodologia Ativa para Aprendizagem Significativa com Apoio de Tecnologias Inteligentes. In: CONGRESSO INTERNACIONAL DE INFORMÁTICA EDUCATIVA, 18., 2013, Porto Alegre. Anais [...]. Porto Alegre: Universidad de Chile, 2013. p. 653-656.

SOUZA, S. C.; DOURADO, L. Aprendizagem Baseada em Problemas (Abp): um método de aprendizagem inovador para o ensino educativo. HOLOS, [S.1.], v. 5, p. 182-200, out. 2015. ISSN 1807-1600. Disponível em: <http://www2.ifrn.edu.br/ojs/index.php/HOLOS/article/view/2880>. Acesso em: 08 nov. 2020. doi:https://doi.org/10.15628/holos.2015.2880.

YIN, R.K. Estudo de caso: Planejamento e métodos. 2. Ed. Porto Alegre. Bookman. 2001. 